\title{
BATALLAS POR LA LEGITIMIDAD: CONSTITUCIONALISMO Y CONFLICTO POLÍTICO EN EL PERÚ DEL SIGLO XIX (1812-1860**
}

POR

\author{
NATALIA SOBREVILLA PEREA \\ University of Kent in Canterbury
}

En este estudio mostramos cómo en el Perú las constituciones fueron utilizadas como armas de batalla desde fines del periodo colonial hasta la segunda mitad del siglo XIX. Veremos cómo la legitimidad de los diferentes gobiernos se basó en las constituciones y se cuestionó por ellas mismas. La representación local, las municipalidades, fue uno de los motivos de lucha en todo el periodo.

Palabras clave: Constitucionalismo, Perú, municipalidades, guerras civiles.

\begin{abstract}
Considerando que el destino de nuestra nación ha sido el de constantemente intentar nuevas leyes, dado que la gravedad de los eventos nos ponen en las circunstancias en que nos encontramos en 1821, que sea el pasado por lo menos una lección para el futuro, para que aquellos que han sido llamados a la importante misión de constituir al pueblo dejen atrás sus odios políticos, la preocupación de su escuela de pensamiento, las teorías utópicas y las sugestiones de la vanidad ${ }^{1}$.
\end{abstract}

Estas palabras que introducen el proyecto constitucional preparado en 1859 por el ilustre poeta y político decimonónico, Felipe Pardo y Aliaga, sitúan a los debates constitucionales en el centro de la discusión política. Las

* Este trabajo nació como una reflexión en los Seminarios de Constitucionalismo organizados por Roberto Gargarella y Robert Barros en la Universidad de San Andrés en Buenos Aires en noviembre de 2003 y 2005. Fue presentado en el IBEI en Barcelona en 2005, en SLAS en Newcastle en 2007 y en el Seminario Revoluções de Independencia en Río de Janeiro en diciembre del 2008, donde recibí generosos comentarios. Agradezco la atenta lectura de Pablo Ortemberg y me hago responsable por los errores y omisiones.

1 Lavalle, 1859: XXIII. 
constituciones, desde la introducción de la Carta de Cádiz en 1812, habían sido usadas como instrumentos de batalla por los diferentes grupos que se enfrentaban por el poder. La legitimidad eludía a menudo a quienes detentaban la presidencia y los vicios en el proceso constitucional se esgrimían como poderosos motivos en las confrontaciones que terminaban en revoluciones. El presente trabajo estudia cómo las constituciones fueron utilizadas en las diferentes coyunturas por diversos actores como medios políticos para legitimar sus batallas por el poder. Mostrará cómo la demanda por la representación local, particularmente las municipalidades, fue uno de los motivos de lucha que cruzó todo el período desde que se dieron las primeras elecciones a ayuntamientos bajo la Constitución de 1812 hasta la Ley Orgánica de Municipalidades de 1861, y aún después de ello. El tema del tributo, así como el de las elecciones y quiénes tendrían acceso a elegir y ser elegidos fueron también muy importantes en estos enfrentamientos. Las constituciones son vistas entonces, no solamente como creaciones jurídicas con intención normativa y de cambio de la realidad, sino también como parte del arsenal político con que contaban los actores del momento.

\section{LOS ANTECEDENTES DEL CONSTITUCIONALISMO PERUANO}

El lenguaje de la representatividad, y en particular, su variante constitucional desarrollada durante la ilustración, fue llevado a la práctica en la construcción de los Estados nacionales modernos. Uno de los más estables en emerger, el británico, no ha tenido una constitución escrita y la tradición ha llevado a que la base misma de su estabilidad se centre en la acumulación de legislación. No hay que olvidar, sin embargo, que este arreglo institucional nació también de una revolución que en 1688 resultó en una declaración de derechos, el bill of rights. Esto llevó al afianzamiento de la monarquía constitucional regida por un gobierno parlamentario, resolviéndose los conflictos posteriores por medio de los cambios en la legislación, en vez del recurso a las armas.

La constitución escrita más longeva en el mundo moderno fue la redactada en 1787 y aprobada en los Estados Unidos de Norte América por la Convención de Filadelfia dos años después y reemplazaba los Artículos de Confederación dados seis años antes. La constitución fue vista como la base para el nuevo Estado y se establecieron una serie de estructuras legales que aseguraran la estabilidad. Esta constitución se ha mantenido durante dos siglos y se ha actualizado con enmiendas que se le han ido agregando en coyunturas particulares. La única confrontación civil en los Estados Unidos se debió a la esclavitud ya que cuando se discutió sobre ella se decidió mantenerla fuera del texto final 
para obtener una solución de consenso. Cada Estado tuvo la libertad de abolirla independientemente, pero con el tiempo la convivencia entre Estados con políticas esclavistas distintas se hizo cada vez más problemática llevando en última instancia a la guerra. La estabilidad fue quebrada, pero al vencer el norte sobre el sur se introdujo una nueva enmienda y la constitución se mantuvo intacta.

La experiencia constitucional francesa, también muy influyente en América Latina, fue muy distinta a estas anteriores por ser fruto de luchas revolucionarias. Los enfrentamientos violentos llevaron a la creación de diferentes cartas, siempre con fe que una nueva traería mayor legitimidad. En Francia, el debate comenzó con los Derechos del Hombre que fueron aprobados en 1789, pero las confrontaciones se suscitaron por la diferencia de opiniones respecto a qué instituciones debían de reemplazar el edificio monárquico destruido por la revolución. Después de ésta se pasó de una primera constitución que en 1791 establecía una monarquía, a experimentos muy diversos, como la Constitución Republicana de 1793, o las que bajo Napoleón establecieron el Directorio, el Consulado y el Imperio. Durante la restauración, se dieron nuevas cartas en 1814, y en 1815, culminando en la de 1830, durante el reinado de Luis Felipe de Orleáns; que fue reemplazada primero tras la revolución de 1848 y luego por Luis Napoleón en 1852. La influencia francesa sería importante en Latinoamérica no sólo por su convulsionada experiencia constitucional, sino también por sus aportes teóricos. Fue fundamental la noción emanada de Montesquieu que veía en un «buen» arreglo constitucional una posibilidad de paz y progreso, mientras que Rosseau pensaba que una sociedad era libre de escribir su constitución tan a menudo como fuera necesario ${ }^{2}$.

En el mundo hispánico la constitución dada en Cádiz en 1812 fue la que más influencia tuvo, incluso en los dominios que ya habían dejado de estar directamente bajo la Corona como las Provincias Unidas del Río de la Plata ${ }^{3}$. Las elites de algunas de las colonias que se mantuvieron fieles, principalmente México y Perú, intentaron influenciar el proceso constitucional enviando a sus diputados a Cortes. Las reformas liberales impuestas en el contexto de la carta también conocida como «la Pepa», redundaron en la radicalización del espacio político, con medidas como la abolición de la inquisición y la libertad de prensa entre otras ${ }^{4}$. De acuerdo con François Xavier Guerra, la importancia de la constitución y de las elecciones que la acompañaron fue tan grande que este

\footnotetext{
2 Ver Aljovín, 2000: 22.

3 Ternavasio, 2007.

4 Mónica Quijada estudia esta Carta en detalle y comparándola con las experiencias francesa y norteamericana. Ver Quijada, LXVIII/242 (Madrid, 2008): 15-37.
} 
autor considera que ellas mismas fueron la revolución ${ }^{5}$. La carta fue jurada en todas las regiones americanas aún bajo el poder español, con toda la pompa y circunstancia reservada a las proclamaciones reales ${ }^{6}$. Es importante tener en cuenta, sin embargo, que fueron los procesos dinámicos de negociación que se desataron en América a raíz de la implantación de la constitución, los que llevaron a una «revolución» y no la simple aplicación de un modelo enviado desde Europa. Fue en gran parte debido a las promesas hechas en este contexto que en el Perú se desataron las revoluciones de Huánuco en 1812 y la del Cuzco en 1814. Esta última fue la más importante que se diera durante el período de la independencia, llegando sus protagonistas a controlar todo el espacio sur andino desde Ayacucho hasta La Paz, por unos diez meses.

Las reformas liberales habían comenzado a penetrar en el espacio andino aun antes de que la carta fuera finalizada y las reacciones a las diversas medidas fueron muestra de lo fragmentada que se encontraba la sociedad. Cuando el tributo indígena fue abolido en marzo de 1811, algunos agradecieron la medida a las Cortes, mientras que otros continuaron pagando los impuestos al rey ausente por medio de las contribuciones «voluntarias» ${ }^{7}$. La constitución reforzó estos cambios, primero, al declarar la igualdad entre españoles e indios, y luego, creando gobiernos municipales en todos los pueblos de más de mil habitantes. El impacto de esta última medida fue muy grande, puesto que sus autoridades serían electas anualmente por los ciudadanos; categoría que excluía únicamente a los sirvientes, previéndose que en un futuro se limitaría el sufragio de los analfabetos. El trabajo pionero de Christine Hünefeldt ha mostrado cómo los debates constitucionales penetraron en lo más profundo del territorio andino, «la Constitución fue leída y juramentada en los lugares mas apartados y pudo por tanto hacer surgir respuestas de acuerdo a la situación especifica y concreta de cada uno de estos lugares» ${ }^{8}$.

También en esta línea Nuria Sala i Vila ha mostrado el gran impacto que tuvo la Constitución en las comunidades indígenas, ya que al desaparecer la división legal entre las repúblicas de indios y de españoles, dejaron de existir también autoridades diferenciadas, estableciéndose en su lugar ayuntamientos únicos, los cuales hacían posible que se eligieran indios para cargos municipales en localidades con población mixta ${ }^{9}$. En el trabajo de Sala se pone en evi-

\footnotetext{
5 Guerra, 1992; Guerra y Demelás-Bohy 60 (Toulouse, 1993).

6 Para detalles de la importancia del ceremonial ver Ortemberg, 2008.

7 Sobre la recepción de la abolición del tributo ver O'Phelan, 1 (Lima, 2002): 177. Sala i Vila, 1996.

8 Hünefeldt, 11 (Lima, 1978): 51.

9 Sala i Vila, $42-43$ (Barcelona, 1993): 51-71.
} 
dencia cómo el lenguaje constitucional estuvo presente hasta en pueblos muy alejados y cómo los indios participaron en los procesos electorales municipales, protestando vigorosamente en los casos en que se intentó impedir que se llevaran a cabo. Sin duda la «revolución» — siguiendo la terminología de Guerra- más importante que se dio con la Constitución fue lo que Sala ha denominado el «asalto» del poder local por los criollos y mestizos, quienes la utilizaron como un instrumento para dar legitimidad a sus luchas. Esta autora ve en la forma en que estos sectores buscaron hacerse del poder por las urnas, un claro precedente de lo que ocurriría después de la independencia. Los indígenas no siempre aceptaron esto y en algunos lugares se sublevaron contra las nuevas autoridades electas y las expulsaron del pueblo, restaurando a su varayoq. En otros lugares el conflicto estuvo ligado al tributo y su posible reimplantación, de modo que los indios tuvieron la posibilidad de elegir autoridades que no permitieran el cobro del tributo «voluntario». Allí donde los criollos lograron ser elegidos y optaron por reinstaurar el cobro, la situación se tornó explosiva, no siendo coincidencia que el levantamiento de 1814 tuviera más apoyo en tales espacios y llegara a mantenerse hasta $1816^{10}$.

En su reciente estudio historiográfico sobre el impacto de las Cortes de Cádiz en el Perú, Víctor Peralta concluye que la Constitución tuvo una repercusión muy importante en los Andes. Cuatro son las líneas de investigación más importantes que encuentra: los procesos electorales, el funcionamiento de los ayuntamientos constitucionales y de las diputaciones provinciales, la cuestión étnica y el conflicto interracial y la conformación de una nueva cultura políti $\mathrm{ca}^{11}$. Peralta y Luis Miguel Glave muestran cómo en las elecciones por el municipio de 1813 la rivalidad entre los miembros de la Audiencia - en su mayoría peninsulares - y los criollos miembros del cabildo llegó al enfrentamiento abierto cuando los miembros del sistema judicial impidieron el desarrollo de muchas de las medidas establecidas por la Constitución ${ }^{12}$. Peralta ha expuesto que los criollos en Lima y en el Cuzco «se definieron a sí mismos como "constitucionales" en su afán de oponerse a los peninsulares a quienes pretendieron asociar con el despotismo y la "arbitrariedad" $\gg{ }^{13}$. El cabildo aparece como una institución representativa que pide la aplicación de la Constitución en una batalla legal encaminada a no malgastar el dinero en fiestas para enviarlo a los representantes en Cádiz $^{14}$.

10 Sala i Vila, 42-43 (Barcelona, 1993): 66 y 68.

11 Peralta Ruiz, LXVIII/242 (Madrid, 2008): 67-96.

12 Glave, 2001: 77-97.

13 Peralta Ruiz, 2005: 65-92.

14 Peralta Ruiz, LVI/206 (Madrid, 1996): 107. 
Estos estudios ponen en claro que la lectura del texto constitucional llevó a la radicalización del importante sector de abogados criollos del Cuzco, que reaccionó a las acciones de los absolutistas, quienes contaban entre sus filas a peninsulares y criollos enlazados en una elite regional, encaminadas a controlar el acceso a los primeros a cargos importantes. Si bien Peralta ha demostrado que la revolución de los hermanos Angulo, en alianza con Pumacahua, «nada tuvo que ver con el modelo de gobierno local implantado por los constitucionalistas y fue más bien un intento de otro sector criollo [...] para que la Audiencia formase una junta de gobierno autonomista semejante a la de Buenos Aires» ${ }^{15}$; la revolución impactó en un espacio que se había radicalizado al calor de las batallas políticas inspiradas por las elecciones de los ayuntamientos constitucionales. Éstas, como muestra Sala, ahondaban, a su vez, los conflictos existentes alrededor del tributo. Si bien la revolución del Cuzco se inició gracias al crecimiento de expectativas generado por la Carta de 1812, su evolución condujo a posturas mucho más radicales, como el planteamiento de crear un nuevo imperio con sede en la antigua capital incaica, y al uso de una gran violencia en los enfrentamientos ocurridos en las ciudades de Cuzco, La Paz y Arequipa. La revolución fue derrotada militarmente y la restauración fernandina terminó con el debate constitucional.

La constitución de Cádiz tuvo, sin embargo, un segundo momento de vigencia entre 1820 y 1823 en el llamado trienio liberal, y su reinstauración tuvo importantes repercusiones para la independencia del Perú. El virrey Joaquín de la Pezuela recibió noticias del retorno de la Constitución en julio de 1820 , pero, puesto que no se incluían instrucciones oficiales, logró aplazar la jura hasta septiembre, días antes del desembarco de San Martín en Pisco ${ }^{16}$. A pesar de esta estudiada demora, el mismo virrey detalla en su diario cómo la opinión pública se manifestó a favor de que se jurase la Constitución con la llegada misma de la noticia y menciona la aparición de pasquines pegados en las esquinas que lo acusaban de no haber seguido las órdenes expresas de hacerla jurar. Fue en los meses en que toda la costa estaba bloqueada por las fuerzas de Cochrane y se esperaba la llegada de San Martín cuando se reinició el debate constitucional. En septiembre, la jura siguió el protocolo de las proclamaciones reales y según el virrey, no se vio mucho entusiasmo en la plaza y no se escuchó un solo viva hasta que el oidor Osma lanzó unas monedas de plata a los zambos y negros que seguían la procesión, los cuales gritaron efusivos vítores con la esperanza de que se les lanzaran más monedas. A pesar de que no se

\footnotetext{
15 Peralta Ruiz, LXVIII/242 (Madrid, 2008): 78.

16 Pezuela recibió las noticias de los sucesos de marzo vía La Habana, ver Pezuela, 1947: 728 y 731 .
} 
dieron las manifestaciones violentas insinuadas en los pasquines, una noche se presentaron tres miembros del ejército, entre ellos García Camba, «capitaneando una multitud de Negros y Zambos con hachas encendidas gritando: ¡Salga el Virrey al balcón y viva la Constitución! pero se retiraron, y no hubo novedad aunque estaban calientes» ${ }^{17}$. Este hecho pone en evidencia cómo en el mismo ejército español existían quienes apoyaban a la Constitución y quiénes, como Pezuela, la veían con reticencia.

Con el desembarco de San Martín el debate constitucional se vio envuelto en los rigores de la guerra y el proceso fue muy distinto al que se vivió entre 1812 y 1814, ya que las fuerzas llegadas desde Chile se convirtieron en un poderoso interlocutor interesado también en la discusión de la Carta. El virrey invitó a San Martín a entablar negociaciones y las conversaciones comenzaron el 25 de septiembre en Miraflores, pero no se llegó a ningún acuerdo. Si bien los llegados desde Buenos Aires y Chile estaban abiertos a la posibilidad de jurar la Constitución de 1812, e incluso de instalar un monarca en el Perú - posiblemente de la misma dinastía Borbón - veían como una condición indiscutible que se aceptara la independencia del Perú, algo que Pezuela no podía consentir ${ }^{18}$. Desde Arequipa, el intendente Lavalle escribió al virrey con noticias de cómo unos oficiales junto con unos emisarios enviados por los enemigos intentaron hacerle una revolución «para unirse al partido de los Insurgentes valiéndose del pretexto de anticipar el Juramento de la Constitución de la Monarquía» ${ }^{19}$.

Una vez más las elecciones a los cabildos constitucionales servirían de telón de fondo para la revolución. Once días después de su elección el 28 de diciembre de 1820, el cabildo de Trujillo se declaró independiente y juró luchar por defender la patria hasta derramar la última gota de sangre ${ }^{20}$. En Lima, Pezuela había tomado medidas para evitar que se dieran elecciones al cabildo, siendo de la opinión que se reintegraran los miembros que habían sido electos en 1814. Pese a sus esfuerzos no pudo lograrlo, ya que la misma corporación municipal hizo uso de los decretos constitucionales para forzar la elección de sus representantes, medida que se llevó a cabo a comienzos de diciembre ${ }^{21}$. Esto erosionó la autoridad del virrey, quien se quejaba en enero de la falta de

\footnotetext{
17 Ibidem: 733 y 764.

18 Paniagua Corazao, 2003: 267-268.

19 Pezuela, 1947: 771.

20 Sobre las elecciones ver Paniagua Corazao, 2003: 261, para el acta de independencia de Trujillo ver Varela Orbegoso, 1908: 258-260.

21 Paniagua Corazao, 2003: 258-260.
} 
atención que daba el cabildo constitucional a la policía, de cómo sus miembros se interesaban solamente en desarrollar las medidas que les fueran de utilidad personal y de cómo se hacían cada día sospechosos de estar con la revolución ${ }^{22}$. La pérdida de poder de Pezuela fue tan grande que el 29 de enero de 1821 fue depuesto por el jefe del ejército José de la Serna, un hombre mucho más cercano al régimen liberal español.

Si bien la cuestión constitucional no fue el único factor que llevó a la victoria de los independentistas, fue sin duda uno de los que agudizó las divisiones internas dentro del campo realista, fracturado entre absolutistas y constitucionales. La Serna era un liberal que se había formado durante las guerras napoleónicas y muchos de los hombres que llegaron con él suscribían al liberalismo de tipo gaditano, como el mismo García Camba, quien según Pezuela apoyó la jura de la Constitución con una turba. Enviado por las Cortes, llegó al Perú en marzo el comisionado de paz Manuel Abreu ${ }^{23}$. Abreu logró un armisticio en mayo e incluso consiguió que los dos líderes se encontraran cara a cara en junio, donde se planteó la posibilidad de que La Serna se convirtiera en regente de una monarquía que estaría en manos de un príncipe español. Según Abreu, La Serna estuvo tentado de aceptar, pero no lo hizo. Abandonó Lima y estableció una nueva capital del virreinato en el Cuzco ${ }^{24}$. El conflicto por la independencia peruana continuó durante todo el trienio liberal, y no es una coincidencia que en 1824, cuando ya la Constitución había sido abrogada y el absolutismo volvía a dominar la política española, una vez más la división entre los realistas diera una ventaja importante a los independentistas quienes vencieron en la batalla de Ayacucho. El enfrentamiento entre absolutistas y constitucionalistas llevó a que el general absolutista Olañeta no sólo dejara de obedecer al virrey La Serna, sino que se enfrentara en el campo de batalla al general realista Valdez. Su actuación hizo que Bolívar y Sucre, creídos de que podían ganarlo para su causa por ser criollo, le escribieran agradeciéndole su ayuda $^{25}$.

Los factores constitucionales tuvieron, entonces, un papel relevante en el proceso de independencia peruana. La rebelión mas importante del período, la del Cuzco en 1814, se debió en gran parte a las expectativas creadas por la

22 Pezuela, 1947: 822.

23 John Fisher ha desempolvado el diario de Abreu que hasta 1971 estuvo catalogado erróneamente con los documentos referentes a México en el Archivo de Indias, ofreciendo una nueva mirada de la participación del enviado de las Cortes, ver Fisher 32/1 (Cambridge, 2000): 70 .

24 Fisher 32/1 (Cambridge, 2000): 71.

25 Sobre Olañeta y la independencia de Bolivia ver Roca, 19 (La Paz, 1991): pp. 3-16. 
Constitución, años más tarde, cuando ésta volvió a regir, fue el cabildo constitucional de Trujillo el primero en jurar la independencia y, por último, el conflicto entre absolutistas y constitucionales que se vivió en América jugó un papel importante en el desenlace de la independencia peruana por haber dividido a las fuerzas realistas. Esto se vio primero con la deposición de Pezuela y con la posibilidad de entablarse un dialogo entre los liberales y San Martín, y luego con la negativa de Olañeta a secundar los dictados del virrey y el consiguiente debilitamiento del ejército realista en las vísperas de Ayacucho. Más allá de estas trascendentes coyunturas, la Carta de 1812 fue de gran influencia en el proceso constitucional peruano, que se nutrió de ella aún más que de las constituciones francesas y norteamericana, a pesar de su aprecio por las innovaciones teoréticas que presentaban. Sumado a esto, la Constitución se instauró en el Perú, y fue con ella que comenzó un conocimiento de una nueva práctica política que habría de dominar el período independiente. El vínculo entre el constitucionalismo y el enfrentamiento político que llevó al uso de la violencia tuvo también su origen en este contexto.

\section{LAS PRIMERAS CONSTITUCIONES PERUANAS}

A pesar de que la Constitución de Cádiz puede considerarse la primera en haber regido en el Perú, no se trató de una constitución peruana. Ésta fue la redactada por el primer Congreso Peruano en $1823^{26}$. Cristóbal Aljovín incide en la importancia de estudiar esta experiencia, aún si la constitución estuvo, en rigor, sólo vigente entre noviembre de 1823 y febrero de 1824, porque al igual que la de Cádiz influenció la formación ciudadana del emergente Estado peruano $^{27}$. La Constitución jurada en las plazas públicas, siguiendo las celebraciones de las de Cádiz, fue redactada durante la difícil coyuntura de tener a dos gobiernos, uno en el norte del Perú bajo José de Riva Agüero y otro en Lima presidido por Bernardo de Torre Tagle ${ }^{28}$. Esta Carta, con fuertes reminiscencias de la de 1812, comenzaba estableciendo que la nación peruana se componía de la reunión de sus provincias. Era liberal en extremo por declarar que la

${ }^{26}$ Los textos completos de las constituciones se encuentran en el Archivo Digital del Congreso de la República, la de 1823 se puede ver en http://www.congreso.gob.pe/ntley/ConstitucionP.htm.

27 Aljovín, 2001: 351-378.

28 Para un análisis de las ceremonias ver Ortemberg 2008. Ceremonial para la publicación de la Constitución, 18 noviembre 1823 http://www.congreso.gob.pe/ntley/Imagenes/LeyesXIX/1823107.pdf. 
nación no tenía derecho a decretar leyes que atentasen contra los derechos individuales. Incluía además una cláusula que ha sido interpretada como el derecho de los pueblos a la insurrección si sus derechos eran violados. Era parlamentarista, o según Aljovín, híbrida con características del sistema parlamentario donde el congreso elegía al presidente, aunque el que resultaba elegido no tenía que ser miembro del mismo ${ }^{29}$. El poder del presidente estaba severamente limitado, y en cuanto a la estructura del Estado seguía lo establecido por Montesquieu sobre la división de poderes. Habría dos cámaras que funcionarían de manera similar a las de Estados Unidos con los diputados elegidos por las provincias, mientras que los senadores serían dos por cada departamento. Las intendencias coloniales se convertirían en Juntas Departamentales con miembros elegidos de la misma manera que lo eran los diputados y serían un órgano consultivo de los prefectos.

La influencia de los liberales fue muy importante y esto se vio con claridad en el tema militar. La carta establecía un ejército de línea que cuidaría la seguridad del país, la milicia cívica abarcaría la provincia y la guardia de policía la localidad. Siguiendo de cerca lo ya visto en las constituciones americana, francesa y gaditana, concebía que el militar no era más que un ciudadano armado en defensa de la república en los dos primeros casos y la monarquía en el segundo. Así fue planteada la relación entre el Estado y las fuerzas armadas, confiándose estas últimas a todos los ciudadanos. En cuanto a quiénes tendrían el derecho a esta ciudadanía, la Constitución fue generosa otorgándoles este derecho a todos los hombres casados o mayores de 25 años que tuvieran una propiedad o ejercieran una profesión o arte, o se ocuparan de alguna industria, sin sujeción a otro en clase de sirviente o jornalero. Siguiendo a la de Cádiz, consideró que sólo se exigiría saber leer y escribir a partir de 1840, acusando esta vez al régimen colonial de haber descuidado la educación, aspecto que pronto sería subsanado por el nuevo Estado ${ }^{30}$.

La importancia de la Constitución de 1823 estuvo fuertemente ligada a la manera como fue utilizada para cubrir de legalidad los actos del congreso. Si bien no fue usada, en este contexto de guerra, como arma de lucha política, se tomaron medidas para evitar que el texto fuera adulterado cuando se prohibió su reimpresión sin permiso escrito de los jefes de gobierno ${ }^{31}$. Aun tras la llegada de Bolívar, quien fue invitado por el Congreso para luchar contra los realistas que todavía controlaban el sur del Perú, la Constitución siguió nominal-

\footnotetext{
29 Aljovín, 2001: 373-375.

$30 \mathrm{http}: / /$ www.congreso.gob.pe/ntley/ConstitucionP.htm.

31 Prohibición de reimprimir la constitución, 17 noviembre 1823, http://www.congreso.gob.pe/ntley/Imagenes/LeyesXIX/1823106.pdf.
} 
mente vigente y el Dictador - como fue nombrado en el Perú- apeló a ella cuando le resultó conveniente o necesario investirse con su legitimidad. En enero de 1824 el congreso le reconoció como «pacificador del norte», y poco más tarde le otorgó una autoridad extraordinaria que le permitiría gobernar en las difíciles circunstancias de la guerra ${ }^{32}$. Hasta octubre Bolívar gobernó con un solo ministerio y fue pasada la batalla de Junín cuando, tras retomarse el control de gran parte de la costa, se recurrió a la Constitución de 1823 para la organización de tres ministerios. Solo después de la batalla de Ayacucho, el 21 de diciembre de 1824, Bolívar llamó a la reunión del congreso, que había suspendido diez meses antes, haciéndolo constituyente. Los diputados que no estuvieran inhabilitados deberían reunirse, mientras que los inhabilitados serían reemplazados por sus suplentes ${ }^{33}$.

A pesar de que el congreso era constituyente y que se pensaba escribir una nueva carta, la de 1823 todavía otorgaba legitimidad, siendo a partir del artículo 32 de la misma como se llamó a elecciones municipales en marzo de $1825^{34}$. Es importante, sin embargo, considerar que solamente unos días antes, el mismo congreso le había dado a Bolívar la facultad de «suspender los artículos constitucionales, leyes y decretos, que estén en oposición con la exigencia del bien público en las presentes circunstancias $»^{35}$. Por un lado, la Constitución era letra muerta ya que Bolívar podía suspender todo lo que considerara molesto; por otro lado, se apelaba a ella en busca de legitimidad para las elecciones municipales. El dictador, ahora de viaje por el sur del Perú, habiendo recibido su posición y legitimidad del Congreso Constituyente de 1823, disolvió este órgano legislativo y decretó las elecciones de un nuevo congreso constituyente a reunirse en febrero de 1826. Bolívar ambicionaba redactar una Constitución que se mostrara fuerte y que sirviera para unir en una federación a los países que había liberado, los actuales Panamá, Venezuela, Colombia, Ecuador, Perú y Bolivia. La Constitución de 1826 es conocida también como la Constitución Boliviana - ya que fue allí donde se redactó y aprobó- o vitalicia - ya que la presidencia quedaba encomendada de por vida a Bolívar, quien podía incluso elegir a su sucesor. En el Perú la Carta fue sometida a los colegios electorales y fue aprobada en todas las provincias salvo una. Además

\footnotetext{
32 Declarando que la nación reconoce al general Bolívar como pacificador de las provincias del norte, 3 enero 1824 http://www.congreso.gob.pe/ntley/Imagenes/LeyesXIX/1824002.pdf.

33 Fijando el día en que se reunirá el soberano Congreso Constituyente, 21 diciembre 1824 http://www.congreso.gob.pe/ntley/Imagenes/LeyesXIX/1824026.pdf.

34 Reglamento de elecciones municipales, 3 de marzo de $1825 \mathrm{http}: / / \mathrm{www} . c 0 n g r e-$ so.gob.pe/ntley/Imagenes/LeyesXIX/1825093.pdf.

35 Ley 10 de febrero de 1825 http://www.congreso.gob.pe/ntley/Imagenes/LeyesXIX/ 1825092.pdf.
} 
de la presidencia vitalicia se introdujeron otros cambios conservadores como el de limitar el voto a quienes supieran leer y escribir. De acuerdo con Roberto Gargarella se trataba de una Constitución de corte conservador donde el ejecutivo se situaba en el centro de la organización de poderes y el presidente se convertía en la figura más poderosa del sistema institucional. En palabras de Gargarella podía llamarse una «dictadura constitucional»"

El legislativo se dividiría en tres cámaras, de tribunos (similares a los diputados), de senadores y de censores, que serían vitalicias al igual que el presidente ${ }^{37}$. Este proyecto estaba claramente influenciado por la Constitución francesa del año VIII — modificada el año X - creadora del consulado vitalicio de Napoleón. La solución que daba Bolívar al problema del caudillismo y de la injerencia política de los hombres que habían luchado por la independencia era la de ponerse en el centro mismo del poder constitucional. Bolívar no podía imaginar la posibilidad de gobernar sin tener una carta en la que basar su posición, además de poseer una larga experiencia en redacción constitucional desde los inicios de la revolución en Colombia. Para él, la constitución era la base para la federación, es decir, era posible imaginar la unión desde un texto jurídico. Las juntas departamentales y las municipalidades serían abolidas y este punto sería uno de los más contenciosos cuando cuestionó la legitimidad de la Constitución de 1826. Pese a conocerse como vitalicia, esta Constitución fue la que menos vigencia tuvo en la historia peruana, puesto que sólo rigió por unas pocas semanas. En el momento de la jura, Bolívar ya se hallaba solucionando problemas en Colombia y la posición de sus seguidores en el Perú era muy precaria. Había dejado a Andrés de Santa Cruz encargado del poder ejecutivo, pero en enero de 1827 estalló un motín contra el régimen. Santa Cruz maniobró hábilmente para mantenerse en el poder. Bajo el principio de que era «un deber sagrado del poder ejecutivo descubrir cuál es la voluntad nacional y obedecerla exactamente» organizó elecciones para un nuevo congreso constituyente por considerar problemática la manera en que había sido aprobada la Carta de 1826 puesto que «un gran número de ciudadanos respetables a nombre de los vecinos de la capital han representado al gobierno que dichos colegios electorales carecían de legalidad» ${ }^{38}$. Una vez más, al igual que durante el proceso gaditano, la constitución se ponía en el centro de la lucha, y como los diputados debían de contar con la legitimidad necesaria se dieron dos leyes

\footnotetext{
36 Gargarella, 2005: 115.

37 Ver Constitución Vitalicia, http://www.congreso.gob.pe/ntley/Imagenes/LeyesXIX/182 6020.pdf.

38 Andrés de Santa Cruz, Convocando a un Congreso Constituyente, para el lero de mayo de 1827 http://www.congreso.gob.pe/ntley/Imagenes/LeyesXIX/1827006.pdf.
} 
complementarias al llamado a elecciones. Mientras una decretó que los diputados debían recibir amplias facultades para legislar, otra reestableció las municipalidades que habían sido abolidas al calor de la guerra en enero de 1824 ya que de otro modo el reglamento de elecciones de 1823 no podría utilizarse y la legalidad de las elecciones podría ser cuestionada ${ }^{39}$. La lucha estaba directamente vinculada a la representatividad local.

Las primeras dos constituciones peruanas - 1823 y 1826 - fueron textos jurídicos importantes ya que formaron la base para la construcción de un Estado independiente. A pesar de que ninguna de las dos fue duradera, ambas se asumieron como el basamento del nuevo Estado y Bolívar apeló a ellas para establecerse y legitimar su poder. La reacción en contra de la Carta vitalicia muestra cómo la cuestión de la legitimidad, o más bien la falta de ella, y los vicios en los procesos electorales en un espacio donde se habían abolido las municipalidades, llevaron al levantamiento de enero de 1827. Tal fue la importancia de este punto, las elecciones al Congreso Constituyente se efectuaron utilizando las municipalidades de 1823, nuevamente establecidas.

\section{LOS CAUDILLOS Y LAS CONSTITUCIONES DEL SIGLO XIX}

Siguiendo la propuesta de Aljovín, es importante tener en cuenta la relación simbiótica que se desarrolló entre los caudillos y las constituciones durante el siglo XIX ${ }^{40}$. Es necesario, sin embargo, considerar que esta relación se gestó no solo en los primeros años de la independencia sino también en los últimos años de la colonia, cuando se puso en práctica la Constitución de Cádiz. Fue allí que comenzó el aprendizaje del lenguaje y de las prácticas constitucionales que abrieron el espacio político a las luchas que buscaron legitimarse por medio de los textos constitucionales. Los diputados elegidos en 1827 e instalados en el nuevo congreso constituyente de junio de ese año fueron casi los mismos que estuvieron encargados de la redacción de la Constitución de $1823^{41}$. La ambición de los constitucionalistas era instaurar el federalismo, pero temían que debido a problemas limítrofes tanto en el norte como en el sur, el Perú pudiera perder parte de su territorio. Hicieron entonces énfasis en la creación de las juntas departamentales que ya se habían visto en 1823 y que

39 Restableciendo las municipalidades en toda la República, 30 enero 1827 http://www.congreso.gob.pe/ntley/Imagenes/LeyesXIX/1827008.pdf.

40 Aljovín, 2000.

41 Prohibiendo las fiestas cívicas por instalación del Congreso, 8 junio 1827 http://www.congreso.gob.pe/ntley/Imagenes/LeyesXIX/1827021.pdf. 
eran un legado gaditano. Sin embargo, una importante innovación fue que estas juntas serían las que propondrían al poder ejecutivo ternas de los candidatos a las prefecturas. Estaban compuestas por dos representantes y un suplente por cada provincia, pero en los años que funcionaron no llegaron a tener real injerencia política ${ }^{42}$. De la misma manera las municipalidades se mantuvieron en la base del sistema político, ya que desde ellas emanaba la legitimidad.

La ciudadanía se extendió a todos los hombres mayores de 21 años o casados, sin más limitación que haber participado en el tráfico de esclavos, haber aceptado puestos de otras naciones, haber sido condenados a pena grave, haber profesado votos religiosos, ser vago, haber abandonado a su mujer o estar divorciado por culpa suya. Las elecciones, sin embargo, seguirían siendo indirectas a través de los colegios electorales. La forma de gobierno se definía como «popular, representativa consolidada en la unidad» y el Congreso tenía el control sobre el ejército ${ }^{43}$. Para hacer esto más palpable se puso mucho énfasis en que todos sus miembros la juraran en actos públicos. El reglamento detallaba la forma cómo debía jurarse, dónde debían hacerse las ceremonias y las misas elegidas para leerla a todos los feligreses. La lectura pública de la constitución se había visto desde la jura de la Constitución de Cádiz, pero aquí se notaba cierta innovación en cuanto a algunos detalles como la participación de las autoridades municipales. Si bien los miembros de los regimientos ya desde 1812 juraban defender la constitución como cuerpos de manera separada ${ }^{44}$, en este reglamento se introducía una nueva manera de jurar:

¿Juráis a Dios y por la cruz de vuestra espada, guardar y hacer guardar la Constitución política de la Republica, que ha sancionado el Congreso constituyente: que no abusaréis de la fuerza que os ha confiado la nación para subvertir los sagrados derechos que la Constitución declara y afianza: que no obedeceréis al jefe que os mande contra ellos o contra la representación nacional, o la inviolabilidad de sus miembros y que antes si os tornareis contra el como ciudadanos armados en guarda de la libertad? ${ }^{45}$

A pesar de que la Constitución de 1828 limitaba los poderes del ejército y ponía al parlamento por encima del poder ejecutivo, en la práctica fue un instrumento que permitió a Agustín Gamarra controlar el poder en los años que

\footnotetext{
${ }^{42}$ Ver Constitución de 1828, http://www.congreso.gob.pe/ntley/Imagenes/LeyesXIX/18280 18.pdf.

43 http://www.congreso.gob.pe/ntley/Imagenes/LeyesXIX/1828018.pdf.

44 Sobre los juramentos de los militares de la Constitución de Cádiz ver Ortemberg, 2008: 506 para el ceremonial de 1812 y Ortemberg, 2008: 529 para el de 1820.

45 Detallando el ceremonial para la promulgación y juramento de la Constitución, 26 marzo 1828 http://www.congreso.gob.pe/ntley/Imagenes/LeyesXIX/1828021.pdf: 3.
} 
estuvo en la presidencia entre 1829 y 1834 . Esto apunta a que en realidad lo mas importante para los caudillos de este tiempo era tener una base sobre la cual construir su legitimidad. Gamarra tuvo que enfrentar muchos levantamientos y motines durante su período presidencial, pero logró mantenerse y argumentar que su poder, con todos sus vicios, era legítimo y constitucional, a pesar de ser acusado de déspota por miembros del congreso.

La Carta de 1828 incluía una cláusula que llamaba a su reforma en cinco años, así que Gamarra, interesado en hacer cambios constitucionales de tipo conservador que le permitieran continuar en el poder, llamó a la convención nacional en 1833 para que se dedicara a las reformas necesarias. Las variaciones que realizaron con respecto a la Constitución vigente fueron mínimas. Los principales cambios consistieron en suprimir las juntas departamentales y negar el voto a los soldados, sirvientes, jornaleros y mendigos. También se introdujo la posibilidad de que el país se pudiera organizar como una federación con algún otro, porque ya se comenzaba a trabajar por una posible unión con Bolivia.

La convención de 1834 se enfrentó al poder de Gamarra por la controversia sobre la sucesión presidencial. Las constituciones peruanas - con la excepción lógicamente de la vitalicia - no permitían la reelección presidencial inmediata y como el mandato de Gamarra estaba por concluir, el enfrentamiento se centró en quién tenía el derecho de elegir a su reemplazante. La convención consideró que era su potestad, ya que no había tiempo para llamar a otras elecciones. Como Gamarra no apoyaba al miembro del ejército elegido a la presidencia, el país se vio envuelto en una revolución. Ambos bandos acusaban al otro de sobrepasar su potestad constitucional. Gamarra imputó a la convención no tener la legitimidad para elegir a un nuevo presidente y ésta le criticó el usar de ese argumento como un pretexto para mantenerse en el poder. Los liberales, de la mano del presidente electo Luis José de Orbegoso, lograron vencer. A pesar de estar avalado por la nueva Constitución de 1834 y de ser un miembro del ejército, Orbegoso tuvo una presidencia débil, marcada por la oposición de Gamarra y las negociaciones con el presidente de Bolivia, Andrés de Santa Cruz, quien proponía crear una Confederación entre Perú y Bolivia. La situación política llevó a que la unión de estos dos países llegara a darse en una coyuntura muy confusa de guerra civil. Gamarra y los enemigos de este proyecto fueron al exilio y en el Perú se buscó legitimidad mediante un nuevo proceso constitucional que comenzó en 1837. El Perú se dividiría en dos Estados, el Nor-Peruano y el Sur-Peruano, y junto con Bolivia serían una Confederación. Aljovín ha mostrado cómo el presidente de Bolivia vio a la Confederación como una posibilidad constitucional, pactando con Orbegoso no sólo porque se trataba de un aliado más débil y por ende más fácil de con- 
trolar, sino también porque su posición tenía más legitimidad constitucional ${ }^{46}$. Para justificar su intervención en el Perú, Santa Cruz se remitió al pedido de auxilios que le había hecho el congreso peruano en 1834. Diciendo que

«reclamaron los auxilios del de Bolivia, y esta reclamación estaba apoyada en los votos de la nación entera. Innumerables comunicaciones privadas de los hombres más respetables del país estaban en perfecta consonancia con los llamamientos públicos y legales del Cuerpo Legislativo y de la Administración» ${ }^{47}$.

Santa Cruz legitimaba su opción de participar en los negocios peruanos con el llamado que había hecho su mismo congreso y luego con la autoridad que emanaba de haber sido vuelto a llamar por Orbegoso, quien se apoyó en una asamblea en Arequipa para hacerlo. Su respuesta a la creación de una nueva legitimidad, al igual que el intento de Bolívar, fue constitucional, ya que llamó a tres asambleas constituyentes a que decidieran la mejor manera de crear la Confederación de los que serían tres Estados. En su discurso ante la Asamblea de Sicuani es muy claro al detallar que «las determinaciones tomadas en el tumulto de los bandos legislativos, han sido siempre funestas; y quizá en el Perú, el origen de la anarquía que lo ha devorado» ${ }^{48}$. La estabilidad, a juicio de Santa Cruz, sólo se conseguiría con la construcción de leyes sólidas. Los males vividos por el Perú se debían, entonces, a la forma en que se habían dado las leyes, que describía como decisiones tomadas por «el tumulto».

Al igual que Bolívar, Santa Cruz creía en un ejecutivo fuerte. En cuanto al tema indígena, reintrodujo muchas de las instituciones coloniales como la de protector de indios, restituyó las tierras de los curacas, e ideó una cadena de mando que iba desde los prefectos hasta los alcaldes indígenas, pasando por los subprefectos y gobernadores. También restituyó a los indios las tierras comenzadas a vender desde 1825 bajo los criterios liberales de Sucre y Bolívar. Según Aljovín esto se debió al paternalismo de Santa Cruz que no consideraba a los indios ciudadanos ${ }^{49}$. Sin embargo, es legítimo preguntarse, tomando en cuenta la larga duración, si quizás la intención de Santa Cruz habría estado más bien ligada a mantener el apoyo de los indios que veían en estas instituciones importantes salvaguardas de sus derechos.

Esta ambiciosa unión tuvo muchos enemigos. En el Perú se desconfiaba de la organización en dos estados por temerse que sería el comienzo de la división del país, mientras que en Bolivia se consideraba que el Perú siempre ten-

\footnotetext{
46 Aljovín, 2005: 96-115.

47 Santa Cruz, 1835: 2.

48 Santa Cruz, 1836: 2.

49 Aljovín, 2005: 108 y 111.
} 
dría mayor capacidad decisoria ya que se trataría de dos estados contra uno. En Chile se temía que el nuevo vecino del norte se convirtiera en un enemigo muy poderoso, lo que favoreció que los emigrados peruanos en Chile y el gobierno de ese país acordaran impedir esa unión. Después de dos campañas bélicas el proyecto de Santa Cruz murió en 1839. Gamarra fue el vencedor político de la derrota de la Confederación y una vez instalado como presidente provisorio por las tropas chilenas trabajó para que se redactara una nueva constitución que reemplazaría la que lo había sacado del poder en 1834. La Carta de 1839 se promulgó en Huancayo — de donde recibió su nombreporque las tropas chilenas todavía ocupaban Lima. Todos los representantes que la redactaron eran cercanos a Gamarra mientras que quienes habían trabajado por las dos constituciones anteriores fueron alejados del legislativo por haber apoyado la Confederación. Aunque se trató de una redacción nueva y no de una modificación de la Carta existente, se mantuvieron muchos de los elementos de las anteriores. Conservaba la división de poderes, y la ciudadanía se daba a todos los hombres mayores de 25 años o casados que pagasen una contribución y supieran leer y escribir, con excepción de los indios y mestizos, que podrían ser analfabetos hasta 1845 . Las elecciones seguían siendo indirectas, pero la ciudadanía podía perderse por participar en algún levantamiento contra el gobierno. El período presidencial se extendía de cuatro a seis años y los municipios fueron abolidos. El congreso se reuniría cada dos años y el presidente gobernaría con el apoyo de un Consejo de Estado compuesto por quince miembros. Esta Constitución, fuertemente inspirada por la carta chilena de 1833, abolía no solamente las municipalidades, sino también las juntas departamentales y la vicepresidencia.

En 1841 se produjo una revolución contra Gamarra desde las provincias del sur que habían favorecido a la Confederación. Dijeron hacerlo porque:

\footnotetext{
«la constitución, nombre usurpado sacrílegamente, era la tremenda carta donde se hallaban consignados los caprichos de la ambición: No había derechos, no había garantías; cualquiera de vosotros podía ser expatriado, o ir impunemente al cadalso a la voluntad de un Bajá» ${ }^{50}$.
}

Los rebeldes fueron derrotados. Gamarra decidió intentar terminar con la injerencia de los aliados de Santa Cruz en Bolivia, así que invadió el país vecino y encontró la muerte en la batalla de Ingavi en noviembre de 1841. Su fallecimiento provocó una crisis constitucional, ya que la persona que debía reemplazarlo y llamar a elecciones al presidente del Consejo de Estado fue atacado

50 Valentín Boza, «El Ciudadano General de la División del Sur a los habitantes del departamento del Cuzco, 31 diciembre 1840», El Comercio, 11 de enero de 1841. 
por dos caudillos, uno en Lima y el otro en el Cuzco, que casi simultáneamente lo derrocaron. En la capital el pronunciamiento se hizo «debido a las circunstancias», mientras que el del sur se basó en la constitución, aduciendo que el presidente del Consejo de Estado no estaba actuando con independencia por lo que el segundo vicepresidente tomaba el poder para garantizar las elecciones. La situación en este período, conocido en la historia peruana como el de la anarquía, se complicó aún más porque ninguno de estos caudillos logró establecerse con suficiente fuerza, y el conflicto llevó a que un tercero se instalase como Supremo Director en 1843.

La estancia de éste en el poder fue corta porque, a pesar de haberlo obtenido con la promesa de restituir el mandato de la constitución, una vez en el mando cambió de opinión al considerar que la de 1839 había sido:

tachada por ser de origen vicioso, [y que] ha sido frecuentemente combatida por los diferentes partidos políticos en que se ha dividido la República, y es actualmente rechazada por una gran parte de la nación [...] Que la instalación o nueva convocatoria de un Congreso emanado de leyes fundamentales que han perdido fuerza moral, y cuya misma existencia se ha hecho cuestionable. Sería arrogarse el derecho de imponer a la nación instituciones desautorizadas, y quizás odiosas, contrariando así el voto de los pueblos, en que se apoya la misión y el poder del gobierno presente ${ }^{51}$.

Como respuesta a esto, el Director proponía llamar a una nueva asamblea constituyente para que redactara una nueva carta. Vemos entonces cómo la cuestión constitucional estaba en el centro mismo del conflicto. Por un lado, los diversos aspirantes a la presidencia remitieron a la constitución para buscar una legitimidad, pero al mismo tiempo cuestionaron la legalidad de la Carta de 1839. De esta manera una vez más convertían a la constitución en un instrumento de lucha política.

Mientras en Lima el Director buscaba organizar un nuevo Estado apelando a una nueva legitimidad que emanaría de un nuevo proyecto constitucional, en el sur del país comenzó una revolución en su contra. Organizada desde las provincias de Moquegua, Tacna y Tarapacá, se articuló en defensa de la Constitución de 1839 y sus autores se autonombraron constitucionales. Buscaban crear un Estado paralelo, por lo que establecieron su propio servicio postal e, incluso, una corte de justicia con sede en la ciudad de Ayacucho ${ }^{52}$. El deseo de los líderes estaba claramente definido como el de devolver «el imperio de las le-

51 El Peruano, 10 mayo 1843.

52 Ayacucho, 18 de marzo de 1844, Copiador de notas cambiadas entre las autoridades políticas de los departamentos de Ayacucho y Huancavelica, D10426 Manuscritos de Biblioteca Nacional de Lima. 
yes fundamentales del Estado ${ }^{53}$. El argumento de la falta de legalidad del régimen establecido en Lima fue también utilizado en la capital cuando Vivanco salió a luchar contra la revolución en el sur. Un civil, el coronel de milicias que se había quedado encargado de la ciudad con sus hombres, Domingo Elías, llamó en su pronunciamiento al fin de la intervención de los caudillos en la política. Elías consideraba que ya que no había ninguna base legal para establecer un gobierno legítimo por parte de ninguno de los bandos militares en contienda, él se había visto forzado a tomar el poder hasta que se instalara en congreso $^{54}$. Los constitucionales vencieron finalmente y, a pesar de que Elías quiso ser un interlocutor válido desde Lima, no se lo tomó en cuenta y se volvió a instalar al presidente del consejo de Estado para que organizara las elecciones presidenciales. Fue elegido quien había dirigido la campaña: Ramón Castilla.

Al haber regresado el poder al presidente del Consejo de Estado como mandaba la constitución y buscado, por lo menos públicamente, no tener ninguna injerencia en las elecciones, el nuevo presidente se vio en la posibilidad de investirse de la legalidad constitucional. Castilla había sido uno de los principales ministros de Gamarra y durante su período en el gobierno de 1845 a 1851 se hicieron importantes reformas constitucionales, principalmente en temas de comercio exterior y organización de la república ${ }^{55}$. Se legisló sobre la policía, las prefecturas y el presupuesto y se hicieron importantes mejoras financiadas con los recursos que obtuvo el gobierno gracias a la exportación del guano. Una de las reformas más importantes de la presidencia de Castilla fue la del ejército, ya que por primera vez desde la independencia fue posible reducir el número de efectivos dándoles una compensación económica que evitara el descontento ${ }^{56}$. Además, una de las innovaciones más trascendentales de esta administración fue la reinstalación de las municipalidades abolidas en $1839^{57}$. La ley sobre las mismas ponía un fuerte énfasis en el manejo presupuestario:

«Las municipalidades en el momento de ser instaladas, reasumirán la administración de los propios y arbitrios de los pueblos, la que practicarán por medio de te-

53 Carta de Ramón Castilla al Secretario de la Suprema Junta, Andahuaylas, 23 enero 1844 en Archivo Castilla, Lima: Instituto Libertador Ramón Castilla, 1967, vol. II, p. 168.

54 Para un estudio detallado del caso ver Peralta Ruiz, 1999: 231-252.

55 Sobre las reformas electorales ver Peloso, 1996: 186-211.

56 Ver Sobrevilla Perea, 2005: 130-133.

57 Archivo del Congreso de la República (ACR): Cámara del Senado «Actas del Congreso Ordinario de $1845 », 25 .^{\circ}$ sesión, viernes 1 de agosto 1845 . Hasta qué punto se llegaron a implementar no queda claro; y el texto de esta ley no está incluido en la Colección Digital del Congreso y sólo hay una mención de ella en los debates constitucionales y en Sivirichi, 1965: I, 147-148. 
soreros especiales con finanzas y responsabilidad, donde dichas rentas rindan de cuatro mil pesos para arriba, y por medio de un individuo de su seno en los pueblos donde rindan menos; pero bajo la misma responsabilidad de finanzas» ${ }^{58}$.

No cabe duda que la cuestión municipal estuvo imbricada de manera central con la cuestión de la legitimidad constitucional, y que una de las maneras como Castilla legitimó su posición tuvo que ver con el interés que puso su régimen en introducir cambios constitucionales claves como el del retorno de las municipalidades. Los conflictos que se dieron entre los años de 1830 y 1840 manifestaron cómo la legitimidad constitucional podía ser utilizada por todos los bandos como una bandera de reivindicación que justificara los levantamientos. Fue apelando a la constitución y al modo en que los vicios en la elección la habían violentado cómo se atacó a Orbegoso, mientras él apeló a su posición de presidente legal para mantenerse en el cargo. De una manera muy similar, Santa Cruz se acercó al lado que percibió como más legitimo en términos constitucionales e intentó organizar la confederación por un fiat legal. Gamarra, al retornar al poder, buscó un nuevo arreglo constitucional, pero no le fue sencillo conseguir consenso para gobernar. Tras su muerte, el edificio constitucional se desplomó, pero fue rescatado por un grupo de caudillos que apeló a la legalidad para hacerse del poder. Una vez en la presidencia, Castilla asentó su posición mediante una reforma constitucional que restituía las municipalidades.

\section{LAS LUCHAS CONSTITUCIONALES DE MEDIADOS DEL SIGLO XIX}

Después de casi cuarenta años de experiencia constitucional en el Perú, se había llegado a un arreglo que comenzaba a parecer estable. La Constitución de 1839, tan cuestionada desde el momento mismo de su redacción, se había convertido en un texto legitimado por el proceso mismo de revolución y que tras la llegada de Castilla al poder había sido reformado de manera extensa. Estas reformas habían hecho posible que reclamaciones antiguas y persistentes como el retorno de las municipalidades se incluyera en el pacto político. En 1850 por primera vez en la República fue posible que un gobernante llamara a elecciones presidenciales para elegir a su sucesor. A pesar de que éstas fueron bastante reñidas y algunos acusaron a Castilla de querer perpetuarse en el poder mediante un cambio constitucional que le permitiera la reelección, se dio una transición pacífica del mando. Durante los debates electorales apareció un

58 ACR: Cámara de Diputados «Actas del Congreso Ordinario de $1845 », 30 .^{\circ}$ sesión, jueves 5 de junio de 1845 . 
grupo autodenominado progresista que explicaba la importancia de las constituciones como espacios políticos desde donde construir la legitimidad: «Los pueblos han tenido que conquistar su libertad con las armas en mano y han sellado con su sangre sus constituciones ${ }^{59}$.

El nuevo presidente, José Rufino Echenique, fue, sin embargo, cuestionado al poco tiempo de llegar al poder, entre otras cosas, por verse acusado de malversar los fondos que se obtenían del guano y que se estaban utilizando para pagar las deudas contraídas por el Estado durante las guerras de la independencia y los primeros años de la República. Sindicado de corrupción y en la mira de la joven generación de liberales que se incorporaba a la vida política de la nación, el presidente se enfrentó a una revolución encabezada por el ex presidente Castilla. Uno de los argumentos principales para ello fue que las elecciones presidenciales no habían sido legítimas porque se había cometido fraude a gran escala ${ }^{60}$. El publicista chileno Francisco Bilbao que se hallaba exiliado en Lima escribió sobre los motivos que llevaban a la revolución de la siguiente manera:

«si no se piensa en ley, en justicia, en reforma, en cumplir las promesas hechas a los pueblos, en reformar la Constitución, en organizar las municipalidades republicanas, la Guardia Nacional, en castigar el impudor, en fomentar la moralidad, en libertar la industria y sólo se piensa en explotar, a la infeliz Nación, en llenarla de ignominia» ${ }^{61}$.

Un vez más aparecían las municipalidades como un eje central de la lucha política y como una de las reivindicaciones más importantes. Esto a pesar de que el gobierno mismo buscaba darle mayor autonomía a los gobiernos locales como lo muestra el discurso del ministro de Gobierno de Echenique, quien decía: «es necesario pues, que la Legislatura dé vida a la personalidad de cada pueblo, volviendo a la República la existencia del Municipio, que le fue arrebatado en una época bastante lamentable de nuestra historia» ${ }^{62}$. La ley orgánica de municipalidades dada el 16 de noviembre de 1853, detallaba no sólo las atribuciones de los gobiernos locales, sino cómo serían elegidos sus miembros que se renovarían por mitades cada año63. La legitimidad del régimen se vio, sin embargo, completamente quebrada cuando el congreso otorgó al presiden-

59 El Progreso, Lima, 29 septiembre 1849.

60 Para un estudio detallado de las elecciones ver Ragas Rojas, 2003.

61 Francisco Bilbao, «La Revolución de la Honradez», en El Triunfo del Pueblo, T. XIII, n. ${ }^{\circ} 13$, Cuzco 24 mayo 1854.

62 Tirado, 1853: 22.

63 Ley Orgánica de Municipalidades, 16 noviembre 1853, ver: http://www.congreso.gob.pe/ ntley/Imagenes/LeyesXIX/1853138.pdf. 
te facultades extraordinarias, ya que de ahí en adelante sus enemigos políticos podían asegurar que el gobierno carecía de legitimidad constitucional. Se dio entonces la situación de que el mismo militar que había luchado por reimponer la Constitución de 1839 en 1844 buscara terminar con ella porque le impedía retomar el poder. La revolución de 1854 si bien tuvo a Castilla a su cabeza fue en gran medida un levantamiento de las regiones y de la juventud enardecida por las ideas de cambio que se habían popularizado después de los eventos acaecidos en Europa en $1848^{64}$.

Durante esta revolución se dieron dos importantes medidas liberales: la abolición del tributo indígena y de la esclavitud ${ }^{65}$. El decreto de la abolición de la esclavitud detallaba la importancia del proceso de cambio constitucional de la siguiente manera:

«Que la regeneración política, proclamada por los pueblos para corregir los abusos monstruosos de la administración del General Echenique, tiene el fin esencial de hacer prácticos los derechos de la libertad, igualdad y propiedad, escritos en la Constitución de la República y de hacer en adelante imposibles las dictaduras deshonrosas, fundadas sobre el envilecimiento de las masas» ${ }^{66}$.

Una vez de regreso a la presidencia, al deber su legitimidad a las actas populares que lo aclamaron, Castilla no tuvo mas remedio que convocar a los treinta días de pacificada la República una asamblea constituyente que debía redactar una nueva constitución y a la que él tenía que dar cuenta de todos sus actos.

Las elecciones de 1855 fueron las primeras en dar el voto directo a todos los hombres, incluyendo a quienes hasta hacía muy poco habían sido esclavos. El voto, sin embargo, estuvo restringido para quienes habían apoyado al gobierno derrocado, asegurándose entonces que la convención estuviera dominada por los liberales. Las primeras acciones de ésta fueron elegir a Castilla presidente provisorio y derogar la Constitución de 1839. Su relación con el ejecutivo fue desde el inicio muy tirante, iniciándose el conflicto por el tema de los ascensos militares. La situación se tornó cada vez mas tensa hasta que se llevó al punto en que la asamblea discutió la posibilidad de declarar vacante la presidencia. Los representantes fieles al gobierno lograron evitar que eso ocurriese, pero las relaciones entre el legislativo y el ejecutivo continuaron siendo difíciles.

64 Para un estudio de esto ver Sobrevilla Perea, 2002.

65 Sobre la revolución ver Sobrevilla Perea, 2004.

66 Ramón Castilla y Pedro Gálvez, «Decreto de Abolición de la Contribución de Indígenas, Ayacucho 5 de julio 1854», en El Triunfo del Pueblo, t. XIII, n. ${ }^{\circ}$ 27, Cuzco, 22 julio 1854. 
Entre las innovaciones más importantes de la Constitución de 1856 estaban la creación de un consejo de ministros y el retorno de la figura del vicepresidente que reemplazarían al Consejo de Estado. Volvieron a instaurarse las municipalidades y las juntas departamentales, estas últimas con potestad de elegir a los prefectos. La nueva ley orgánica de municipalidades, si bien no fue tan extensa como la anterior, detalló, una vez más qué poblaciones tendrían derecho a gobiernos locales y cómo se debía llevar a cabo las elecciones, además de las atribuciones de todos sus miembros ${ }^{67}$ y el número de autoridades en cada una ${ }^{68}$. La Convención abolió los fueros militares y eclesiásticos, la pena de muerte, la propiedad de los empleos, los derechos hereditarios y las vinculaciones. Todos estos cambios fueron considerados revolucionarios y amplios sectores de la población, especialmente los grupos más católicos y el ejército, estuvieron en su contra por atentar contra los privilegios de sus corporaciones. La posición de los convencionales en contra del ejército fue clara cuando en sus debates se dijo: «la ciega obediencia del militar a su Jefe a convertido al Ejército en instrumento del Poder Ejecutivo contra los pueblos y las instituciones ${ }^{69}$. Se obligó además a que todos los ascensos se tuviesen que ser ratificados por el congreso.

El gobierno de Castilla pidió a la Convención que reconsiderara la abolición de los fueros, la propiedad de los empleos y la ratificación de los ascensos militares, pero ésta se mantuvo en su postura original. Castilla se vio decepcionado por el resultado y al jurar la Constitución de 1856 dijo que solamente la respetaría en cuanto fuera buena para el país. Su correspondencia con el obispo de Arequipa muestra que todavía tenía fe en que ésta podía reformarse y no consideraba el proceso terminado. Los conservadores de esa ciudad no estuvieron contentos con el resultado y en cuanto se promulgó la constitución tomaron las armas para luchar en su contra argumentando que

«el Erario Nacional ha sido entregado al agio y monopolio de los adeptos del General Castilla [...] que después de haberle dictado la Constitución que debía sancionar, ha ideado la farsa de obedecerla, para desprestigiar ese alto Poder, con el objeto de hacerlo odioso y perpetuar su Dictadura - que la Convención humillada y por satisfacer al Dictador ha sancionado una Constitución anómala, antirreligiosa, inoportuna y contraria a la opinión nacional ${ }^{70}$.

${ }^{67}$ Ley orgánica de municipalidades, 29 noviembre, 1856 ver http://www.congreso.gob.pe/ ntley/Imagenes/LeyesXIX/1856083.pdf.

68 Ley transitoria de municipalidades, 29 diciembre 1856, http://www.congreso.gob.pe/ ntley/Imagenes/LeyesXIX/1857002.pdf.

69 Citado en Paz-Soldán, 1943: 99.

70 Acta de la Revolución de Arequipa, 31 octubre 1856, El Registro Oficial del Departamento, n. ${ }^{\circ} 21$, Cuzco, 8 noviembre 1856, p. 59. 
La revolución de Arequipa llevó a Castilla a abandonar la capital e ir a luchar contra los que llamó «jóvenes inexpertos e inmorales» que se dedicaban a quemar copias de la Constitución ${ }^{71}$. Los alzados veían en la problemática legitimidad de la misma la base para su levantamiento

Esa bastarda carta tiene pues en su contra, no solo las resistencias de la sociedad, sino las prevenciones que excitan sus autores, y aunque fuera un modelo de sabiduría inspirada por la Divinidad misma; desde que es IMPUESTA por un partido victorioso y sin misión; desde que se le quiere propagar por el poder de la fuerza y de las bombas, [...] ella no puede ser la constitución de la familia peruana la ley fundamental sobre la que debe estribar inconmovibles todas las columnas de nuestro edificio $^{72}$.

Resultó además en el cierre de la Convención por un coronel que decía hacerlo en nombre del gobierno pero sin ser una orden directa del presidente que se hallaba ausente. Ello fue visto con alivio por el gobierno, que hizo todo lo posible por distanciarse del autor de esta medida.

Aunque la Convención, tan hostil a Castilla, ya no existía, la Constitución seguía en vigencia. Una vez que los rebeldes fueron derrotados le fue necesario buscar una fórmula para llevar al cambio constitucional que deseaba. La solución se encontró en las actas populares que comenzaron a aparecer por todo el país pidiendo que se modificara la Carta de 1856. El tema de la reforma constitucional era muy importante para el presidente ya que consideraba que estaba al centro mismo de su legitimidad:

Verificada la adhesión, sería consecuencia forzosa de ella convocar un Congreso extraordinario que restableciese la legalidad y pusiese término a la crisis. El mismo Congreso podría encargarse de revisar la Constitución, suprimiendo en ella las innovaciones extemporáneas que rechaza el buen sentido nacional, conforme a las indicaciones que los pueblos hagan en las actas electorales ${ }^{73}$.

Se hicieron nuevas elecciones en 1858 de las que resultó Castilla presidente constitucional. Este congreso no hizo, sin embargo, los cambios que quería el presidente. Impaciente con este resultado y ad portas de una guerra con Ecuador, Castilla logró que cerrara el congreso y llamó a uno nuevo en 1860 sobre el que tuvo mas control. La carta reformada de 1860 obtuvo el consenso que Castilla buscaba, manteniendo algunas de las reformas liberales como la abolición de los fueros y las vinculaciones eclesiásticas, pero reintroduciendo

71 Ramón Castilla, Proclama, Lima, 26 noviembre 1856, Archivo Castilla, vol. II, p. 29 .

2 Sánchez, 1857: 22.

73 Carta de Ramón Castilla a Manuel Ortiz de Zevallos, Sacacha 2 diciembre 1857, Archivo Castilla, vol. VI, p. 131. 
la propiedad de los empleos y la pena de muerte. Las elecciones dejaron de ser directas y se quitó la referencia al sufragio, dejándolo para ser decidido a través de un reglamento aparte. También desapareció la mención a las juntas departamentales, pero estas fueron reimpuestas por medio de leyes complementarias. Los municipios fueron limitados en sus atribuciones, aunque se escribió una ley particular para regularlos. En suma, muchos de los cambios mas liberales desaparecieron, pero algunos importantes se mantuvieron, fue por ello que esta Constitución se ha descrito siempre como moderada y ha sido la más longeva que ha tenido el país — rigió por más de 60 años- . La Constitución de 1860 logró sobrevivir muchos cambios de régimen, desde el primer civil en la presidencia, pasando por revueltas y revoluciones, y en 1867 el reestablecimiento por unos meses de la Carta de 1856. Pero incluso en el difícil contexto de la posguerra con Chile, dicha Constitución logró mantenerse en gran medida porque era suficientemente amplia y podía reformarse con relativa facilidad.

El constitucionalismo fue entonces un proceso muy intenso durante todo el siglo XIX, poniéndose en práctica entre 1812 y 1860 constituciones de diversos contenidos ideológicos. Todas buscaron organizar el Estado y recomponer la legitimidad que comenzó a tambalear a raíz de la captura del rey en 1808 . Las batallas por la legitimidad fueron constantes y muchos de los temas más polémicos se repitieron de manera casi cíclica por más de medio siglo. La lucha por consolidar los gobiernos locales y las municipalidades fue recurrente y muy importante para la movilización de las provincias desde el inicio mismo de la experiencia constitucionalista en 1812. Las constituciones fueron usadas por los distintos actores desde fines del período colonial hasta la segunda parte del siglo como bandera para los levantamientos y cambios políticos. Después de mucha experimentación y muchos enfrentamientos se llegó en el Perú a un arreglo moderado que se mantuvo en vigencia hasta comienzos del siglo XX. Sin embargo, la ambición de cambiar el mundo por medio de la legislación no desapareció y se dieron nuevas constituciones en 1919, 1933, 1979 y 1993; y, como se ve en Latinoamérica, esta aspiración todavía no ha desaparecido. Muchas de las naciones que se independizaron de España hace ya casi dos siglos siguen buscando aún hoy un nuevo y más perfecto orden constitucional.

\section{BIBLIOGRAFÍA}

Aljovín de Losada, Cristóbal, «A Break with the Past? Santa Cruz and the Constitution», Nils Jacobsen y Cristóbal Aljovín (eds.), Political Cultures in the Andes, Durham, Duke University Press, 2005: 96-115. 
Aljovín de Losada, Cristóbal, «La Constitución de 1823», Scarlett O’Phelan Godoy (ed.), La Independencia en el Perú: De los Borbones a Bolívar, Lima: PUCP, 2001: 351-378.

Aljovín de Losada, Cristóbal, Caudillos y Constituciones, Perú: 1821-1845, Lima: Fondo de Cultura Económica, 2000.

Fisher, John, «The Royalist Regime in the Viceroyalty of Peru, 1820-1824» en Journal of Latin American Studies, 32/1 (Cambridge, 2000): 55-84.

Gargarella, Roberto, Los fundamentos legales de la desigualdad: el constitucionalismo en América (1776-1860), Madrid, Siglo XXI, 2005.

Glave, Luis Miguel, «Antecedentes y naturaleza de la revolución del Cuzco en 1814 y el primer proceso electoral», Scarlett O'Phelan Godoy (ed.), La Independencia en el Perú: De los Borbones a Bolívar, Lima: PUCP, 2001: 77-97.

Guerra, François-Xavier y Demélas-Bohy, Marie Danielle, «Un processus révolutionnaire méconnu: l'adoption des formes representatives modernes en Espagne et Amérique, 1808-1810», Caravelle, 60 (Toulouse, 1993): 5-57.

Guerra, Françoise-Xavier, Modernidad e Independencias, Mexico: Fondo de Cultura Económica [1992], 2000.

Hünefeldt, Christine, «Los indios y la constitución de 1812», Allpanchis XI (Lima, 1978): 35-58.

O'Phelan, Scarlett, «Ciudadanía y etnicidad en las Cortes de Cádiz», Elecciones, 1:1 (Lima, 2002): 165-185.

Ortemberg, Pablo, «Rituel et pouvoir: sens et usages des liturgies civiques. De la Vice-royauté du Pérou à l'orée de la République (Lima, 1735-1828)», Tesis Doctorado, EHESS-Paris, 2008.

Paniagua Corazao, Valentín, Los orígenes del gobierno representativo en el Perú. Las elecciones (1809-1826), Lima: PUCP y Fondo de Cultura Económica, 2003.

Pareja Paz-Soldán, José, Historia de las Constituciones Nacionales, Lima: Grafica Zenit, 1943.

Peloso, Vincent, «Liberals, Electoral Reform, and the Popular Vote in Mid-Nineteenth-Century Peru» en Vincent Peloso y Barbara Tennenbaum (eds.) Liberals, Politics and Power: State Formation in Nineteenth Century Latin America, Athens and London: Georgia University Press, 1996: 186-211.

Peralta Ruiz, Víctor, «El impacto de las Cortes de Cádiz en el Perú. Un balance historiográfico» en Revista de Indias LXVIII/242 (Madrid, 2008): 67-96.

Peralta Ruiz, Víctor, «Los inicios del sistema representativo en Perú: Ayuntamientos constitucionales y Diputaciones provinciales (1812-1815)», en Marta Irurozqui Victoriano (ed.), La mirada esquiva. Reflexiones históricas sobre la interacción 
del Estado y la ciudadanía en los Andes (Bolivia, Ecuador, Perú), siglo XIX, Madrid, CSIC, 2005: 65-92.

Peralta Ruiz, Víctor, «El mito del ciudadano armado, la "Semana Magna" y las elecciones de 1844 en Lima» en Hilda Sábato (ed.) Ciudadanía política y formación de las naciones, México, Fondo de Cultura Económica, 1999: 231-252.

Peralta Ruiz, Víctor, «Elecciones, constitucionalismo y revolución en el Cuzco, 1809-1815», Revista de Indias, LVI/206 (Madrid, 1996): 99-131.

Pezuela, Joaquín de la, Memoria de Gobierno del Virrey Joaquin de la Pezuela, Virrey del Perú 1816-1821, Sevilla: Escuela de Estudios Hispano-Americanos, 1947.

Proyecto de Constitución Política, escrita por el Sr. Felipe Pardo y Aliaga y presentado a la Convención Nacional por los SS Diputados Quiros, Ballón, Terry (D.J.), Ferry (D.J.M.) y Tejada. Con algunas explicaciones y comentarios por José Antonio de Lavalle, Lima: Tipografía Alfaro, 1859, p. XXIII, segunda edición.

Quijada, Mónica, «Una Constitución singular. La Carta Gaditana en perspectiva comparada», Revista de Indias, LXVIII/242 (Madrid, 2008): 15-38.

Ragas Rojas, José, «Cultura política, representación y modernidad en el Perú: La campaña electoral de 1850», tesis de licenciatura, PUCP, 2003.

Roca, José Luis, «Pedro Antonio de Olañeta y el proceso formativo del Estado Boliviano». Historia y Cultura 19 (La Paz, 1991): 3-16.

Sala i Vila, Nuria, Y Se Armó el Tole Tole: Tributo Indígena y Movimientos Sociales en el Virreinato del Perú, 1784-1814, Ayacucho, Instituto de Estudios Regionales José María Arguedas, 1996.

Sala i Vila, Nuria, «La constitución de Cádiz y su impacto en el gobierno de las comunidades indígenas en el virreinato del Perú», Boletín Americanista, $42-43$ (Barcelona, 1993): 51-71.

Sánchez, Hipólito, Vencer o morir, Arequipa: Tip. Francisco Miranda, 1857.

Santa Cruz, Andrés de, Exposición de los motivos que justifican la cooperación del Gobierno de Bolivia en los negocios políticos del Perú, La Paz, Imprenta del Colegio de Artes, 15 julio 1835.

Santa Cruz, Andrés de, Mensaje de S.E. El Jefe Superior del Ejercito Unido dirijido a la Asamblea de Sicuani en su instalación, Cuartel General en Sicuani a 16 de marzo de 1836.

Sivirichi, Atilio, Historia del Senado del Perú, Lima, Cámara de Senadores, 1965.

Sobrevilla Perea, Natalia, «Caudillismo in the Age of Guano: A Study in the Political Culture of mid-Nineteenth Century Peru (1840-1860)», PhD Dissertation, Universidad de Londres, 2005. 
Sobrevilla Perea, Natalia, «El proyecto Liberal, la Revolución de 1854 y la Convención de 1855», en Carmen McEvoy (ed.), La Experiencia Burguesa Peruana, Madrid: Iberoamericana, 2004: 223-243.

Sobrevilla Perea, Natalia, «The Influence of the European Revolutions of 1848 in Peru», en Guy Thompson (ed.), 1848 in the Americas, Londres, Institute of Latin American Studies, 2002: 191-216.

Ternavasio, Marcela, «Nuevos principios constitucionales y acción política. El Río de la Plata en tiempos de revolución». Paper presentado en la Conferencia de SLAS, Newcastle, 15 abril, 2007.

Tirado, José Manuel, Memoria de Gobierno, Relaciones Exteriores, Culto y Obras Publicas, Lima: Imprenta de Gobierno, 1853.

Varela Orbegoso, Luis, Documentos del Gran Mariscal D. Luis José de Orbegoso, 3 vols., Lima: Imprenta Liberal Unión, 1908.

\section{BATTLES FOR LEGITIMACY: CONSTITUTIONALISM AND POLITICAL CONFLICT IN PERU IN THE 19th CENTURY $(1812-1860)$}

This study shows how between the end of the colonial period until the second half of the nineteenth century constitutions were used in Peru as tools for battle. We see how each different government based its legitimacy on the constitution, and how they were also used when this legitimacy was called into question. Local representation, municipalities in particular were one of the reasons for fighting during this whole period.

Key words: Constitutionalism, Peru, municipalities, civil wars. 